\title{
MENINGITIS BACTERIANA RECURRENTE EN PACIENTES CON MALFORMACIÓN DE OÍDO INTERNO. SERIE DE CASOS
}

\section{RECURRENT BACTERIAL MENINGITIS IN PATIENTS WITH MALFORMATION OF INTERNAL EAR. CASE SERIES}

\section{Santiago Luis VALLEJOS-RIART ${ }^{1}$, Jorge Luis ROIG-OCAMPOS ${ }^{\mathbf{1}}$.}

${ }^{1}$ Universidad Nacional de Asunción, Facultad de Ciencias Médicas, Cátedra y Servicio de Otorrinolaringología, San Lorenzo, Paraguay.

Cómo citar este artículo: Vallejos-Riart SL, Roig-Ocampos JL. Meningitis bacteriana recurrente en pacientes con malformación de oído interno. Serie de casos. Med. clín. soc. 2019;3(1):27-33.

\section{RESUMEN}

Las meningoencefalitis bacterianas recurrentes (MEBR) constituyen un reto diagnóstico y terapéutico. Entre los factores predisponentes podemos citar las malformaciones de oído interno. Se presentan tres pacientes, dos pediátricos y uno adulto, que sufrieron episodios de meningitis bacteriana recurrente asociados a fístula trans ótica de líquido cefalorraquídeo (LCR) con malformación del oído interno, que fueron sometidos a cirugía para cierre de fístula. Pretendemos con este trabajo compartir nuestra experiencia y discutir diferentes opciones diagnósticas y terapéuticas en situaciones semejantes.

Palabras clave: Meningitis; oído interno; anomalías.

\section{ABSTRACT}

Recurrent bacterial meningoencephalitis (RBEM) is a diagnostic and therapeutic challenge. Among the predisposing factors, we can mention the inner ear malformations. We present three patients, two pediatric and one adult, who suffered episodes of recurrent bacterial meningitis associated with trans-cerebrospinal fluid fistula (CSF) with malformation of the inner ear, who underwent surgery to close the fistula. We intend with this work to share our experience and discuss different diagnostic and therapeutic options in similar situations.

Keywords: Meningitis; inner, ear; abnormalities.

\section{INTRODUCCIÓN}

Las meningoencefalitis bacterianas recurrentes (MEBR) constituyen un reto diagnóstico y terapéutico. Se han identificado como factores predisponentes los déficits de inmunidad humoral y celular y los defectos estructurales congénitos o adquiridos. De entre los defectos estructurales congénitos están las malformaciones de oído interno (1-2). 
La primera clasificación de anomalías congénitas cocleares ha sido propuesta en 1987 por Jackler y col. Fue ampliamente aceptada, la cual divide las anomalías congénitas cocleares con relación al tiempo en que se detuvo el desarrollo durante la gestación $(3,4)$ (Tabla 1).

TABLA 1: CLASIFICACIÓN DE LAS ANOMALÍAS MORFOLÓGICAS DEL OÍDO INTERNO (PROPUESTA EN 1987 POR JACKLER Y COL)

\footnotetext{
a. Aplasia del laberinto o deformidad de Michel (3 semana)

b. Aplasia coclear ( 3 a 4 semana)

c. Cavidad común de la cóclea y vestíbulo (principio de la 5 semana)

d. Anomalía cocleovestibular quística o partición incompleta Tipo I (final de la 5 semana)

e. Hipoplasia coclear (6 semana)

f. Partición incompleta tipo II o displasia de Mondini (7 semana)
}

La prevalencia de anomalías anatómicas del oído interno y del conducto auditivo interno visualizadas por tomografía axial computadorizada en la población con hipoacuisa sensorioneural congénita es del $20 \%(1,7)$ y de ellos, en el $65 \%$ afecta a ambos oídos, y el 35\% es unilateral (1). Este tipo de anomalía puede asociarse a fístulas de fluido cerebroespinal espontaneas, llevando a episodios de meningitis recurrentes que va del 30 a 93 \% según la literatura consultada $(5,6)$.

Según los autores el diagnóstico de fístula LCR al oído medio podría ser considerado cuando presenta antecedentes de meningitis recurrente, pérdida auditiva sensorioneural y malformaciones de la cápsula ótica evidenciadas en la tomografía (3). La detección del germen causal a través de la punción lumbar también puede orientar al sitio probable de origen del proceso infeccioso $(1,2)$.

La RM y la CT con contraste intratecal (cisternografia) fueron citados como una opción en varios trabajos $(5,6,8)$, aunque con la desventaja de los falsos negativos en los cuadros fistulosos intermitentes (5). También se citan otras técnicas como el contraste con la fluoresceína y los isótopos radioactivos inyectándolos en el espacio subaracnoideo y permitiendo hacer un diagnóstico topográfico del origen de la fístula $(4,5)$.

Varios autores consultados realizan el cierre de la fístula a través de la estapedectomia y llenado del vestíbulo con músculo $(1,5,8)$, otros complementan dicho procedimiento con relleno del oído medio con gordura $(1,5)$ y otros inclusive obliteran la trompa de Eustaquio y rellenan la cavidad dentro del contexto de una cavidad radical (8). En una situación donde no se encontró el punto fistuloso se optó por la laberintectomía y oclusión del defecto con musculo y grasa abdominal (9). Solamente un autor, de la literatura consultada, se refirió al control de la presión de LCR por punción y colocación de un catéter peridural en el espacio subaracnoideo (9).

El cierre quirúrgico de una fístula transótica puede llevarse a cabo en 3 sitios anatómicos: en las ventanas del oído interno, en la fosa craneal posterior y en el oído interno displásico propiamente dicho a través de las ventanas o por laberintectomia. En un oído con audición residual útil, se recomienda realizar timpanotomía más colocación de injerto sobre la fístula, esto está indicado como un primer intento, aunque con esta técnica la recurrencia de la fístula es común. Cuando esta técnica falla y aún hay audición, se realiza un abordaje por fosa 
craneal posterior y colocación de músculo como tapón en el conducto auditivo interno (CAI) o tejido conectivo sobre el trayecto fistuloso. Cuando la audición es pobre, un abordaje directo a través del oído displásico es recomendable. Después de una timpanotomía, se remueve la platina, y se utiliza un pedazo de fascia para obliterar el vestíbulo. Si la anatomía no es favorable se recomienda un abordaje translaberíntico para obliterar el CAI (10).

Se presentan tres pacientes, dos pediátricos y uno adulto, que sufrieron episodios de meningitis bacteriana recurrente asociados a fístula trans ótica de líquido cefalorraquídeo (LCR) con malformación del oído interno, que fueron sometidos a cirugía para cierre de fístula. Pretendemos con este trabajo compartir nuestra experiencia y discutir diferentes opciones diagnósticas y terapéuticas en situaciones semejantes.

\section{PRESENTACIÓN DE LOS CASOS CLÍNICOS}

Caso 1. Niño, 7 años que presenta antecedentes de diez episodios de meningitis bacteriana, algunos por Haemophilus influenzae no tipificable, otros por Neumococo y los demás sin datos registrados. Al examen físico la membrana del tímpano se presenta intacta pero opaca, resto del examen sin particularidades. Por tomografía se constata ocupación del oído medio por imagen de densidad de partes blandas y malformación del oído interno lado izquierdo (Fig 1).

Los potenciales auditivos del tronco encefálico (PATE), evidencian hipoacusia sensorioneural severa en oído izquierdo y normalidad a la derecha. Se sospecha en fistula LCR hacia oído medio como punto de partida de la meningitis. Es sometido a dos cirugías por técnica conservadora sin éxito. En un tercer intento se decide obliterar el vestíbulo. Se prepara al paciente con catéter peridural en el espacio subaracnoideo para disminuir la presión del LCR a nivel de la fístula. Se procede a la timpanotomía exploradora y cierre de fístula: como hallazgo intraoperatorio se constata una fistula con débito importante por delante de la ventana oval. Se remueve el yunque para mejora exposición.

Se remueve el estribo exponiendo la ventana oval con salida abundante de LCR. Se procede al llenado del vestíbulo con músculo, consiguiendo controlar la salida de LCR, se cierra la ventana oval con cartílago con pericondrio y sobre el mismo, músculo más pegamento biológico. Se llena la caja timpánica y mastoidea con trozos de músculo y se reposiciona el colgajo meatotimpánico. Se mantiene el drenaje lumbar por 3 días y se lo medica con azetazolamida y cefazolina. Recibió el alta a los 10 días del posoperatorio. Hasta la fecha no ha presentado meningitis. Su último control audiológico evidencia pérdida sensorioneural moderada del lado contralateral y actualmente es usuario de audífono convencional de ese lado y con buen aprovechamiento. 


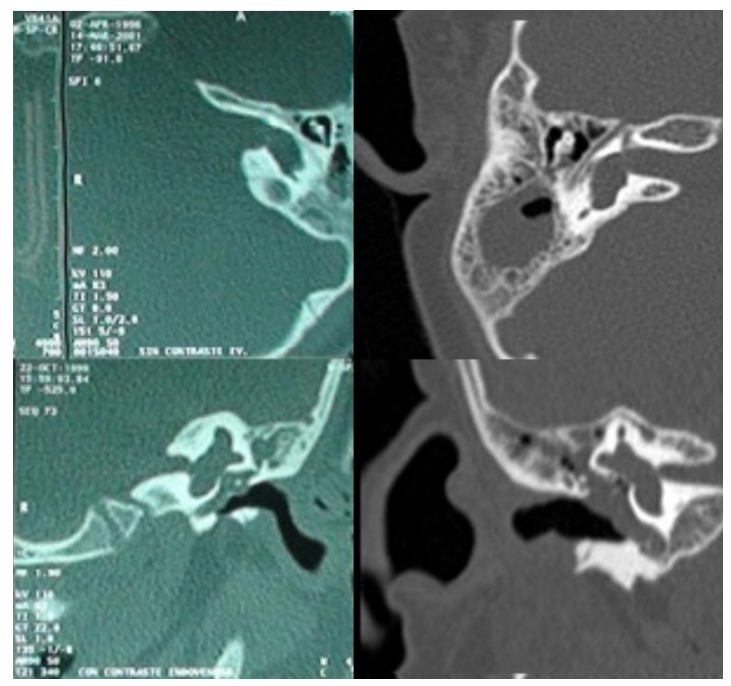

Fig. 1. Imagen izquierda: primer caso clínico. TC coronal simple evidenciando alteración morfológica de la cápsula ótica y ocupación de la caja del tímpano por imagen de densidad de partes blandas. Imagen derecha: segundo caso clínico.TC corte coronal y axial sin contraste evidenciando la alteración conformacional del oído interno y ocupación parcial del oído medio por imagen de densidad de partes blandas.

Caso 2. Niño, 4 años, que presenta cuatro episodios de meningitis desde los dos años de edad, consulta con estudio de imagen con sospecha de mastoiditis, al examen se constata un tímpano intacto pero opaco y al reevaluar las imágenes tomográficas se evidencia una malformación del oído interno y ocupación parcial del oído medio derecho por imagen de densidad de partes blandas (Fig. 1). La audiometría lúdica y PATE evidencian una hipoacusia sensorioneural profunda en oído derecho. Se sospecha en fistula LCR hacia oído medio como punto de partida de la meningitis. Se realiza timpanomastoidectomia exploradora y cierre de fístula. Se coloca catéter peridural en el espacio subaracnoideo con el mismo objetivo del primer caso clínico.

Se constata mucosa de caja normal y mastoides libre de patología, se extrajo el yunque para mejor exposición, se constata fistula de poco débito en región superior de ventana oval, se remueve el estribo exponiendo el vestíbulo y se procede a la obliteración del mismo con músculo, se ocluye la ventana oval con cartílago con pericondrio y ventana redonda con músculo más fascia, pegamento biológico y sobre esta, nuevamente pericondrio, se rellena la caja timpánica con trozos de músculo y se reposiciona el colgajo meatotimpánico. Se mantiene el drenaje lumbar y como medicación la azetazolamida y ATB. Se le dio el alta a los 10 días del posoperatorio. Hasta la fecha, no presentó episodios meníngeos.

Caso 3. Adulto, 50 años, masculino, sordomudo, presenta antecedentes de tres episodios de meningitis desde hace dos años. Encaminado por su infectólogo con estudio de imagen con sospecha de mastoiditis. Hace 3 años sufre un traumatismo de cráneo sin pérdida de conocimiento y nota también en el mismo período rinorrea clara de forma intermitente del mismo lado. La tomografía de oído evidencia hipoplasia de la cóclea y un agrandamiento del modiolo en su polo basal bilateralmente.

Se confirma la sospecha de fístula LCR de oído con la cisternografia por resonancia magnética (Fig. 2). Se descarta también un compromiso a nivel de techo de nariz y senos paranasales. Se opta por la obliteración del oído medio. Se constata en el intraoperatorio una fístula a nivel de la ventana redonda y una desarticulación del yunque con el estribo y fracturas de la crura del estribo. Se cierran ambas ventanas con tejido fibroso y pegamento biológico, se 
oblitera trompa con musculó previa descarificacion, se rellena la cavidad radical con grasa autóloga y se cierra el conducto auditivo externo en fondo de saco. El paciente evoluciona satisfactoriamente, hasta la fecha no presento cuadro meníngeo.

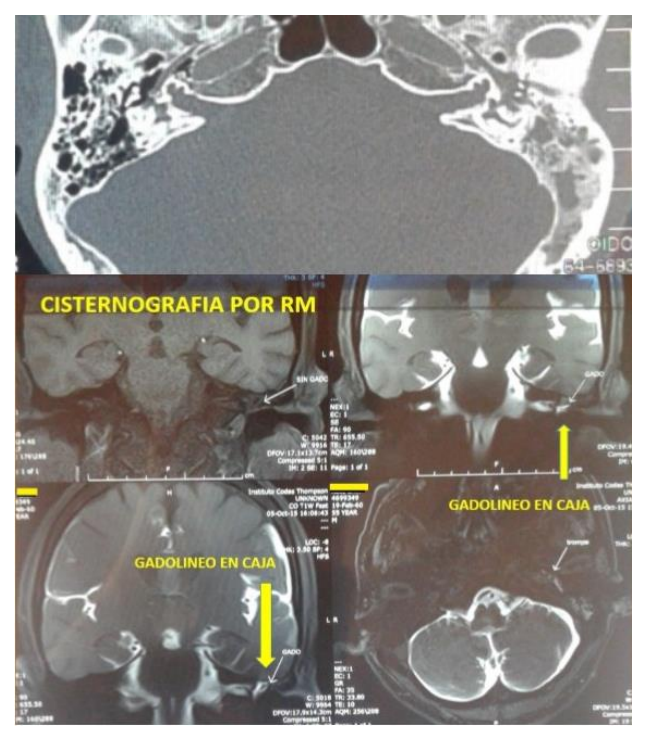

Fig. 2. Imagen superior: TC sin contraste, axial, evidenciando la hipoplasia coclear con ensanchamiento de la columela y amplia comunicación con el CAI. Imagen inferior: Resonancia magnética con contraste intratecal, evidenciándose la fístula LCR en oído medio.

\section{DISCUSIÓN}

Se presentan tres casos clínicos que, dentro de las anomalías morfológicas del oído interno $(1,2,3,4)$, corresponden, los casos pediátricos a una partición incompleta Tipo I y el del adulto a una hipoplasia coclear (Tabla 1). Estos tipos de anomalías pueden asociarse a fístulas de fluido cerebroespinal espontaneas y a episodios de meningitis recurrentes $(5,6)$.

El diagnóstico de fístula LCR al oído medio puede no ser tan simple, más aún cuando es de poco débito, pero podría ser considerado cuando presenta antecedentes de meningitis recurrente, pérdida auditiva sensorioneural y malformaciones de la cápsula ótica evidenciadas en la tomografía (3). Nuestros tres pacientes presentaron episodios recurrentes meníngeos e hipoacusia sensorioneural profunda, evidenciándose a través de una TC la malformación cocleovestibular y ocupación de las cavidades del oído medio que podría corresponder a una otopatía secretora crónica o eventualmente a la presencia de LCR, o sea, contábamos con los tres elementos citados por Graham et al, para sugerirnos el diagnóstico de fístula LCR en oído medio.

Quiero resaltar que los tres pacientes fueron encaminados con el diagnostico probable de mastoiditis, solicitando la evaluación por el especialista y sugiriendo realizar una mastoidectomia. Los estudios especializados tanto audiológicos como tomográficos, nos orientaron a un diagnóstico más exacto y por ende a un tratamiento más efectivo. La tomografía como herramienta para el manejo de este tipo de pacientes se considera como la mejor opción $(1,7)$ y el conocimiento temprano por parte del familiar y del profesional de la existencia de una malformación, permitiría una mejor orientación a los familiares con respecto a los cuidados en este tipo de situación, por ejemplo, considerar la vacunación anti-neumococo, evitar deportes violentos, etc. 
Los gérmenes detectados en nuestros pacientes: Streptoccocus Pneumoniae y Haemóphilus influenzae, no tipificable, están relacionados a infecciones de las vías respiratorias altas abalando su posible foco otogénico, coincidiendo con los autores sobre el valor de la punción lumbar en el topodiagnóstico (1,2). La RM con contraste intratecal (cisternografia) fue una herramienta útil para nuestro paciente adulto y debe ser considerado como una opción diagnostica en ciertos casos $(5,6,8)$. Una vez hecho el diagnostico presuntivo, el manejo de este tipo de problemas es esencialmente quirúrgico.

En base a la literatura consultada podemos decir que el abordaje quirúrgico en estos pacientes va depender de: el estado funcional del oído afectado y del grado de malformación (10). Pero considerado nuestros casos clínicos, todos con audición residual nula, el denominador común en la mayoría de los autores consultados fue el cierre de fístula a través de la estapedectomia y llenado del vestíbulo con músculo $(1,5,8,9)$. En nuestros casos clínicos pediátricos, la obliteración del vestíbulo con músculo a través de la ventana oval fue el procedimiento elegido y con buenos resultados, aclarando que utilizamos multicapas de injertos que incluyeron músculo, fascia, cartílago y pegamento biológico sobre la ventana oval. Ya el paciente adulto optamos por la obliteración del oído medio y también hasta hoy día con resultado favorable.

Con esto podemos concluir en base a nuestra experiencia y a la literatura consultada que

1- el manejo de este tipo de afección es complejo, uno por el tiempo prolongado entre el primer episodio meníngeo y el diagnóstico definitivo y dos en lo que respecta a las diversas conductas terapéuticas evidenciadas en la literatura.

2- el tipo de cirugía a realizar va depender de la localización de la fístula, del estado funcional de oído afecto y sobre todo de la experiencia del cirujano otólogo.

Esperamos con este trabajo aportar nuestra experiencia para futuros colegas que enfrenten una situación semejante.

\section{CONFLICTOS DE INTERÉS Y FUENTE DE FINANCIACIÓN}

Los autores declaran no poseer conflictos de interés. Fuente de financiación: ninguna.

\section{REFERENCIAS BIBLIOGRÁFICAS}

1. Díaz JV, Garófalo-Gómez N, Rodríguez U, Parra M, E. Barroso-García, Novoa-López L, Rojas-Massipe E, Sardiñas-Hernández NL. Displasia de Mondini: meningitis bacteriana recurrente en la adolescencia. Rev neurol. 2004;39:935-939. https://doi.org/10.33588/rn.3910.2004155

2. Morgenstern Isaak A, Bach Faig A, Martínez $S$, Martín-Nalda A, Vázquez Méndez $E$, Pumarola Segura F, Soler-Palacín P. Meningitis recurrente por defectos anatómicos: la bacteria indica su origen. An Pediatr (Barc). 2015;82(6):388-396. https://doi.org/10.1016/j.anpedi.2014.09.008 
3. Jackler et al. Cita in: Rezaee A, Gaillard F. Cochlear anomalies (classification). [Consultado el 5 de enero 2019] Disponible en: https://radiopaedia.org/articles/cochlearanomalies-classification

4. Saab D S,Fernandez De la Cruz A, Monroy R S, Serrano S, Rodriguez N. Malformación congénita del oído interno bilateral y del conducto auditivo interno derecho en un paciente con hipoacusia profunda neurosensorial bilateral: presentación de caso. Rev. Colomb. Radiol. 2015;26(1):4158-4162. URL.

5. Graham MD, Lundy L B. En: Brackmann DE, Shelton C, Arriaga M, editor. Otológico Cirugía.Filadelfia, Pensilvania: WB Saunders; 1993. Dural hernia y fugas de líquido cefalorraquídeo. pp. 277-288.

6. Savva A, Taylor M, Beatty Ch. Management of cerebrospinal fluid leaks involving the temporal bone: report on 92 patients. Laryngoscope.2003;133:50-56. https://doi.org/10.1097/00005537-200301000-00010

7. Rivera D, Saad S, Córdoba C, Montes G, Barreto T. Malformación congénita del oído interno y conducto auditivo interno en un paciente con hipoacusia neurosensorial profunda bilateral: reporte de caso. Rev Colomb Radiol. 2010; 21(1):2851-2855.URL.

8. Chen Lue AJ, Manolidis S. Intrathecal Fluorescein to localiza cerebrospinal fluid leakage in bilateral mondini dysplasia. Otol Neurotol.2004;25:50-52. URL.

9. Zocchi GA, Mascardi NE, Arana JD, Pace AE, Bodino JA, Benitez AJ. Displasia de Mondini y meningitis bacteriana recurrente: a propósito de dos pacientes. Rev Hosp Niños B Aires. 1999;41(181):16-22.

10. Martínez-Montemayor DC, Paz-Delgadillo DE, Villegas-González M,Treviño-González $\mathrm{JL}$, Santos-Lartigue S. Fístula de líquido cefalorraquídeo como causa de meningitis recurrente en un paciente con displasia coclear. Arch Neurocien.2014; 19(3):169-172. $\underline{U R L}$. 